Published in final edited form as:

Disaster Med Public Health Prep. 2013 February ; 7(1): 46-54. doi:10.1001/dmp.2012.57.

\title{
Intention to comply with mandatory hurricane evacuation orders among Hispanics living along a Coastal area
}

\author{
Belinda M. Reininger, DrPH [Associate Professor, Health Promotion \& Behavioral \\ Sciences], \\ UT School of Public Health-Brownsville, 80 Fort Brown, SPH bldg., Brownsville, TX 78520, \\ 956-882-5161, 956-882-5152 (fax), Belinda.M.Reininger@uth.tmc.edu \\ Sartaj Alam Raja, MA [Statistical Analyst], \\ UT School of Public Health-Houston, 6410 Fannin Street, Houston, TX 77030, \\ alamerica@gmail.com
}

Ana Sanchez Carrasco, MPH,

UT School of Public Health-Houston, 6410 Fannin Street, Houston, TX 77030,

Ana.Sanchez@uth.tmc.edu

\section{Zhongxue Chen, PhD [Assistant Professor, Clinical \& Translational Sciences], \\ UT School of Public Health-Houston, 6410 Fannin Street, Houston, TX 77030, 713-500-7985, \\ Zhongxue.Chen@uth.tmc.edu \\ Barbara Adams, MPH, CPH [Epidemiologist III], \\ Texas Department of State Health Services, Region 11, 601 W. Sesame, Harlingen, TX 78550, 956-423-0130, Barbara.Adams@dshs.state.tx.us, Joseph McCormick, MD, MPH}

\section{James H. Steele [Professor \& Regional Dean], and}

UT School of Public Health-Brownsville, 80 Fort Brown, SPH bldg., Brownsville, TX 78520, 956-882-5166, 956-882-5152 (fax), Joseph.B.McCormick@uth.tmc.edu

\section{Mohammad H. Rahbar, PhD [Professor, Epidemiology and Biostatistics]}

UT School of Public Health-Houston, 6410 Fannin Street, suite 100.21, Houston, TX 77030, 713-500-7901, 713-500-9166 (fax), Mohammad.H.Rahbar@uth.tmc.edu

\section{Keywords}

Mandatory evacuation; Hispanics; Poverty; Public Health; Intention

\section{INTRODUCTION}

\section{Background}

Since the profound devastation of Hurricane Katrina, emergency managers are asking themselves how to successfully evacuate the most vulnerable populations from the wrath of

Corresponding author: Belinda M. Reininger, DrPH, Associate Professor, Health Promotion\& Behavioral Sciences, UT School of Public Health-Brownsville, 80 Fort Brown, SPH bldg., Brownsville, TX 78520, 956-882-5161, 956-882-5152 (fax),

Belinda.M.Reininger@uth.tmc.edu. 
destructive hurricanes. ${ }^{1-4}$ Vulnerable populations, including ethnic minorities, elderly, those living in poverty or with disabilities, women and children have been studied to understand their likely evacuation behaviors in light of mandatory evacuation orders ${ }^{5-789}$ Moreover, storm data suggests that over time we are seeing more disasters worldwide, and with population growth and health and income disparities, seeing more vulnerable people impacted by such disasters during and after the storm. ${ }^{10-1415,16}$ For example, in New Orleans where over $28 \%$ of the population lived below the poverty level prior to Hurricane Katrina, it was reported that 100,000 residents, many of whom were African-American and poor, did not evacuate despite a mandatory evacuation classification. ${ }^{17,}{ }^{18}$ In addition to the risk of Hurricane Katrina-related flooding, those failing to evacuate also faced risk of waterborne infectious illnesses and exposure to toxins due to contamination with septic tank waste, and agricultural, sewage, and industrial waste. ${ }^{19}$ There were over 1,300 deaths as a result of Hurricane Katrina. ${ }^{20}$

To improve preparedness, a clear understanding of intentions to comply with evacuation orders among populations vulnerable to morbidity, mortality and property damage associated with hurricanes is necessary. Behavioral theory suggests that intention, while different than actual behavior, is directly associated with behavior ${ }^{21-25}$ and therefore worthy of examination since the study of evacuation behaviors in real-life scenarios is storm dependent.

In a telephone survey conducted by the Harvard School of Public Health, nearly one in four (23\%) Katrina-affected respondents and $28 \%$ of other high-risk area respondents indicated intention to stay in their homes during a major storm, despite mandatory evacuation order by government officials ${ }^{26}$ Other studies have found intention to evacuate changes depending on the vulnerable populations. ${ }^{927-32}$

Studies examining barriers to evacuation, which help explain the difference between intention to evacuate and actual evacuation, have also been conducted with particular emphasis on vulnerable populations. ${ }^{33-36}$ Income level has been shown to affect decisions regarding evacuation. ${ }^{19}, 20,26,37-39$ For example studies have shown that those with few financial resources, without transportation, and with disabilities ${ }^{27,40}$ comprise a high percentage of individuals who do not or cannot evacuate. Some studies of Katrina evacuees reported that although a car was available for evacuation, there was not enough disposable income for gas and food. ${ }^{37}$ Also, studies of evacuation behavior have found women $^{28,29,41,42}$ and households with children are more likely to evacuate. ${ }^{27,29,43}$ Perceptions of the homestead being at risk has also been found as an important determinant in evacuation decisions. ${ }^{42,44}$ In addition, storm strength, ${ }^{19,39}$ worries that property will be stolen or damaged if left, ${ }^{26,37}$ and concerns over the family unit cohesiveness during and after evacuation ${ }^{37,} 38$ have been discussed as reasons evacuation may not occur.

None of these studies characterize the intention to comply with mandatory evacuation orders specifically among low income Hispanic populations living on the coastline. We therefore conducted this study in an area of the country with extreme poverty and where the majority of the population is Hispanic. This area is found in three counties in southern Texas that lie within 70 miles of the Gulf of Mexico, and prone to hurricanes. Two of these counties are 
categorized as the poorest counties in the United States. ${ }^{30}$ These counties lie along the Mexico border and have an approximate population of 1.15 million inhabitants. ${ }^{30}$ Within these three counties, $32-42 \%$ of families fall below poverty level, and $25-31 \%$ of the population has less than a $9^{\text {th }}$ grade education. ${ }^{30}$ Over $87 \%$ of this community is Hispanic. Given that the counties lie back-to-back with Mexico, it is not surprising that $74-83 \%$ of the population speaks a language other than English at home. ${ }^{30}$ Determining intention to evacuate by demographic and location characteristics in this distinct area of the country would help aid local, state, and federal agencies to improve preparation and evacuation of this population and provide new insight into a vulnerable population facing natural disasters and previously not well characterized.

\section{Study Aim}

The aim of this study is to examine intention to comply with mandatory hurricane evacuation orders by demographic characteristics including ethnicity, age, income, education, acculturation and county of residence and location of the census tract from the shoreline among respondents to a door to door survey in three low income, hurricane prone counties.

\section{METHODS}

Data for this study were taken from a broader study examining the attitudes, beliefs and behaviors regarding hurricane preparedness and evacuation conducted by the University of Texas School of Public Health Brownsville Regional Campus in conjunction with the Texas Department of State Health Services.

A door-to-door questionnaire of residents in three counties was conducted using a two-stage cluster sampling strategy, stratified by county between July 2008 and October 2008. First, a simple random sample from the maximum possible of 172 census tracts across the three counties was selected to identify 48 census-tracts each from the two most populous counties and four census-tracts from the rural county. In the second stage of sampling, individual households were selected in each census tract based on 1-in-10 systematic random sampling, where every $10^{\text {th }}$ house, with $9^{\text {th }}$ and $11^{\text {th }}$ household as secondary options, in all four cardinal directions are surveyed until 30 households were completed in each tract. The census tract was considered the primary sampling unit. ${ }^{45}$

Bilingual research staff held small group training sessions for the sixteen outreach workers collecting data in convenient locations (library, church, and university building) in their county. The five hour training covered consenting procedures, interview techniques, guided practice on all questionnaire items and clarification statements, sampling framework, data security, logistics, and completion of non-responder forms. The community health workers had past data collection experience. Community health workers conducted door to door recruitment in pairs to provide monitoring of data collection procedures, support accurate recording of responses, and safety. Two bilingual project managers regularly observed data collection activities in the field. Any deviations from data collection protocol were addressed individually and if necessary across community health workers as well. 
The final sample included 3,088 households in the 100 census tracts in the three counties. The trained outreach workers interviewed one adult person in each household who had the nearest birthday to date of survey and recorded their responses on the questionnaire form. Prior to interviewing, the outreach workers explained the informed consent, and attained written permission to participate. The outreach workers administered the survey in the participant's language of choice. Refusing to participate was documented according to gender and reason for refusal. ${ }^{45}$ Once the anonymous surveys were completed, the surveys were stored in a secured backpack along with but separated from consent forms until the end of the day when they were delivered to staff and secured in locked file cabinets at the University.

The door-to-door questionnaire was a 73-item instrument that included demographics, reasons for and against evacuation, barriers to evacuation, assessment of medical special need persons in the home and preparedness for a hurricane and took between 40-60 minutes to complete. This survey was based on an instrument used to assess hurricane readiness along coastal counties in $2007^{26}$ but then modified with additional questions and translated into Spanish using backwards and forwards translation.

The Bidirectional Acculturation Scale for Hispanics was used to determine acculturation levels. ${ }^{46}$ Four survey questions regarding language use and acquisition for thinking, reading, and speaking both at home and socially were used in the assessment and contained the following response categories: Spanish, equally Spanish and English, or English. A sum score was created across the four items and cut points were established for acculturation scores. The independent variables of education and income were coded into three categories. We also created a variable to assess distance from the center of each census tract to the shoreline. We measured this distance based on a mathematical algorithm of the shortest distance from a tangential line from coastal path to the epicenter of county. Since distance from shore was the same for all households in the same census tract, in the analysis we considered this as a census level continuous variable, with mean distance of 36.1 miles (ranging from .05 to 70.3 miles).

\section{Statistical Analysis}

Weighted data were used for the analyses. Weighting was done in two distinct, successive phases. The first phase was done by the household level and the second by census-tract level to achieve the overall population weights. In order to generalize the results and avoid potential oversampling, sampling weights were incorporated into the analyses. Incorporating sampling weights provided the correct statistical inference by providing a better estimate of standard error, and hence the confidence interval. We used Survey Analytic Package for STATA $11.1 .{ }^{47}$

Socio-demographic variables were tested for association with the dependent outcome variable; specifically, whether or not an individual intends to comply with a mandatory evacuation order. Independent variables including age, gender, ethnicity, income, education completed, acculturation, number of people in the household, and having homeowner's or renter's insurance were examined by county. Two-sided Pearson's Chi-square tests were 
conducted with the dependent variable dichotomized as intention to comply or not-comply with a mandatory evacuation order and independent variables.

A multivariate logistic regression model and 95 percent confidence intervals for the independent variables were calculated based on variables moderately associated (pvalue $<0.05$ ) with the dependent variable in the bivariate analyses. Independent variables were examined for multicollinearity using the test for tolerance and variance inflation factor. For continuous or ordinal predictors, specifically education level and annual household income, standardized odds ratios are estimated.

\section{RESULTS}

\section{Descriptive Characteristics}

Descriptive data (Table 1) show that survey respondents were mostly female, accounting for three-fourths of all respondents across the three counties (Table 2). The mean age for all three counties was 47 years for the population of people 18 years old or older; and Hispanics were the dominant ethnicity group across all three counties. The mean for the number of people living in one household was 4.1 across the three counties.

Yearly income showed that the majority of each county's population has an income between $\$ 0-\$ 24,999$ per year, which falls in the low-income category of this study's scale. At least $75 \%$ of each county population is low-income.

Education level, acculturation, and owning or not owning homeowner's / renter's insurance varied from county to county. Only $42 \%$ of the population of people 18 years old or older had completed 12 years of school in the three counties. People in all three counties have low preference for English as part of the acculturation assessment.

Pearson's Chi-square tests found that gender, ethnicity education, acculturation and county all are significantly associated with the dependent variable of intention to comply or notcomply with a mandatory evacuation order (Table 2). Female respondents are more likely to intend to follow a mandatory evacuation order than males. Little difference among ethnic subgroups to follow a mandatory evacuation order was found with $92.6 \%$ Hispanics and $90.9 \%$ of whites reporting intention to comply with evacuation orders once declared by the local or federal governments. Those with a higher level of education reported a lower likelihood of following a mandatory evacuation order. Respondents affiliated with Spanish language are more likely to report intention to comply with the orders. Income was not statistically associated with compliance with an evacuation order ( $\mathrm{p}$-value $=0.2$ ).

\section{Logistic Regression}

Only those variables with statistical significance ( $\mathrm{p}$-value $<0.05$ ) by Chi-square tests were included in the weighted logistic regression analysis. The odds of intending to comply with a mandatory evacuation order were lower for younger respondents than for older respondents [AOR=.98; 95\% CI: $(.97 ; 99)]$. 
The odds of intending to comply with a mandatory evacuation order were higher for females than for males [AOR=1.5; 95\% CI: $(1.1,2.2)]$. Females, regardless of ethnicity, display a similar and higher level of intention to follow evacuation orders with no statistical difference in response across ethnicity ( $\mathrm{p}=0.07$ ). Hispanic females show a higher likelihood to follow mandatory evacuation order $[\mathrm{AOR}=1.6 ; 95 \% \mathrm{CI}(1.3,2.0)]$ compared with Hispanic males. In contrast, white males have higher odds of intending to follow a mandatory evacuation order [AOR=1.5; 95\% CI: $(0.6,4.0)]$ compared with white females, however this relationship is not statistically significant. White females have an AOR of 1.9 [95\% CI: (1.1, 3.0)], while white males have AOR of 2.8 [95\% CI: $(1.3,6.2)]$ when compared with Hispanic men. Ethnicity alone did not show any relationship with the outcome; however ethnicity and gender have an interaction effect with the dependent variable.

The odds of intending to comply with an evacuation order for participants who completed high school was higher $[\mathrm{AOR}=1.4 ; 95 \% \mathrm{CI}:(1.02,1.9)]$ than for participants who completed an eighth grade education or less. Among those participants who completed college/ technical school the odds of intending to follow a mandatory evacuation order was lower [AOR $=0.72 ; 95 \%$ CI: $(.53, .97)]$ than those who completed an eighth grade education or less. These differences are not explained by levels of income or by stratifying on income by education.

Respondents who are bi-acculturated with Spanish and English are less likely to intend to follow a mandatory evacuation order $[\mathrm{AOR}=0.5 ; 95 \% \mathrm{CI}$ : $(0.39,0.63)]$ than those highly acculturated with Spanish. A similar response is seen among respondents with highaffiliation with English [AOR=0.6; 95\% CI: $(0.37,0.97)]$ compared with reference subgroup. This observation is not affected when either education or income levels are considered.

The odds of intending to follow a mandatory evacuation order were nine times higher for participants from County Two respondents [AOR=9.3; 95\% CI: $(5.2,16.7)]$ than for County One after adjusting for other covariates such as distance, education level and age.

The probability of intending to comply with a mandatory evacuation order based on census tract distance from the coast line was also investigated. We found that people who live farther from the shoreline were less likely to report intention to follow the mandatory evacuation order. [AOR=.97; 95\% CI: $(.95, .98)]$.

\section{DISCUSSION}

We found high levels of intention to comply with mandatory evacuation orders among this population as a whole. The results of the logistic regression indicate that demographic, acculturation and location variables help to explain significant differences among the populations' intention to comply with a mandatory evacuation order. Participants who are younger are less likely to intend to evacuate under mandatory orders than people who are older. This may be because younger participants feel more invincible in the face of a major hurricane, or that older individuals feel less inclined to want to experience the discomforts associated with hurricanes both during and after a storm comes ashore. 
Participants who completed education above a high school level are less likely to report intention to evacuate under mandatory orders than people who completed less than a high school education. Those with a high school education reported the greatest intention to comply. Residents with higher education may have less trust in local government officials and may not believe the government orders when they proclaim a mandatory evacuation order. Higher education levels also showed a relationship with higher income in our sample. However, income alone was not statistically significant in Chi-square analysis or the logistic regression. This statistical insignificance could be due to the limited variance in the income variable, since the majority of respondents were low income. However, because of the correlation (48) between education and income it may be that people with higher education and economic means feel more able to care for themselves and have greater concern for protecting their households and its contents during an emergency and therefore are less likely to report intention to comply with evacuation orders. Respondents with a Spanish only affiliation were more likely to follow the evacuation orders. These participants could be recent or first generation immigrants to the United States and feel compelled to respond to official government orders.

Participants from County Two located approximately 50 miles inland proved to be more likely to evacuate than participants from the other counties in the sample with at least one boundary at the shoreline after adjusting for the ethnicity, education level, distance from the coast line and other covariates. Examining population characteristics more fully, we find that county two has the highest percentage of Hispanics, is the most densely populated county with large urban areas, and has a slightly higher median income. ${ }^{48}$ We believe that residents from County Two may have greater intention to comply with evacuation orders because they have access to more resources to support evacuation such as urban transportation options and two easily accessible highway routes for evacuation compared to one easily accessible route in the other counties. Additionally County Two hosts by far the greatest number of unincorporated, impoverished neighborhoods (Colonias) along the Texas / Mexico border ${ }^{53}$ many of which area prone to long-term flooding problems post hurricanes.

We also found that in general the closer a census tract was to the shoreline the more likely respondents were to report intention to comply with evacuation orders. Previous studies have also noted that the stronger the storm and the closer one's home is to the shore the greater the probability of the population evacuating..$^{28,43,44,49}$ However, as past hurricanes have demonstrated large storm systems which include flooding and tornadoes in unpredictable paths threaten people living inland as well as along the coast.

We reviewed our findings in the light of the conclusions from large telephone surveys performed by the Harvard School of Public Health in $2005^{26}$ and in $2008^{50}$ across a multiethnic population, in which intended compliance with evacuation orders was lower than in our study. These studies primarily accessed homes with landlines, presumably indicating higher income than our participants, $80 \%$ of whom were low income. Indeed we found that people we sampled with higher income were less likely to intend to comply though income was not statistically significantly associated with stated intentions. Our study has a larger sample size in a single area with higher response rate, door-to-door interviews, and a population that is mainly Hispanic, many of whom live close to the Gulf shore (areas 
specifically omitted in 2007 study). Our data may therefore more accurately reflect the attitudes and intentions of low income Hispanic communities living close to the Gulf.

\section{CONCLUSION}

Overall, this study demonstrates that the vast majority of residents (93\%) living in one low income region prone to hurricanes intend to comply with mandatory evacuation orders regardless of income level. Given that the majority of respondents in this population are low income, their need for assistance with mandatory evacuation scenarios is potentially great.

Based on previous scenarios in other coastal areas where demand outweighed assistance for evacuation among the poor and vulnerable, this study's results provide evidence that preparedness planning does not need to focus on increasing intentions to comply with evacuation orders among Hispanics but rather planning should focus on closing the gap between intention and actual evacuation behaviors during a hurricane.

The percentage of people reporting intention to comply in this survey is greater than in other surveys conducted along coastal areas where approximately $75 \%$ of the population reported intention to comply with mandatory evacuation orders. ${ }^{26}$ It is possible that our reported intention to comply is higher because the survey was conducted during hurricane season and a hurricane made landfall during the study period. However, post-hoc analysis examining intention to evacuate before and after landfall showed no significant differences. Our results may have been influenced by the large number of women responding to the survey, as past studies have shown that women are more likely to evacuate in the face of a storm. ${ }^{28,39,41}$ It is also possible that Hispanic populations, despite having multiple characteristics that would classify them as unable to evacuate in the face of a storm may have high levels of intention to comply. It is difficult to compare our findings to other studies examining intention to comply with mandatory evacuation orders with sample sizes powered to draw conclusions about Hispanic populations because few exist. However, a related study examined actual evacuation behaviors in regions of Florida where the Hispanic population accounted for between $3 \%-32 \%$ of the regional samples. This study found no significant differences in evacuation behavior by ethnicity. ${ }^{39}$ Another study of Hispanic community-based organizations found high levels of willingness to participate in emergency planning (96\%), but lower levels of capacity to do so. ${ }^{51}$ One other possible explanation for our results showing higher than expected intention to comply with evacuation orders could be found in the majority of our sample being lower income and potentially living in home structures that are perceived as unsafe. Other studies have found this belief to influence decisions about evacuation. ${ }^{42-44}$ We are unable to examine this association more specifically because these items were not included in the survey.

Our results show there is significant variation of intention to comply with mandatory evacuation orders by demographic characteristic and geographic location among a three county sample of people likely to be exposed to the ravages of hurricanes. This study suggests the importance of planning to evacuate large numbers of people who reported intending to comply with evacuation orders but who may in the event lack means to do so. Additionally our results would suggest that planning efforts should include recovery and relief plans for those individuals who remained after evacuation orders were issued and 
based on our results would likely include a greater proportion of Hispanic men and individuals educated at a high school level. In addition, we found that individuals in census tracts more distally located from the coastline are less likely to intend to comply with evacuation orders. Therefore, in cases of larger more powerful storms where devastation far from coastline is expected, recovery plans to these distal areas where individuals may have sheltered in place should be considered.

Results from this study suggest that populations with higher affiliation towards Spanish are likely to already possess intention to comply with evacuation orders and populations who report speaking English and Spanish equally or more English are less likely to intend to comply with mandatory evacuation orders. These findings may be useful for emergency managers tailoring messages about evacuation orders in Spanish and English. Spanish language messages should focus on moving audiences from intention to action, whereas English messages need to build support for intention and action. These messages should be consistently given before, during and after the hurricane to provide clear instructions to the intended audience.

Future research should build on the results presented in this study. For example, targeting research to explore dissonance between intentions and actions during evacuation scenarios, particularly among Hispanic populations would be appropriate. Moreover, our results indicate that females are more likely than men to report intention to comply with evacuation orders, although overall both genders report high intention. Future research could include a cultural examination of gender based decision-making regarding evacuation within households in hurricane prone areas. Also, given that within this region prone to hurricane damage, census tract and county differences regarding compliance with mandatory evacuation orders was found, a study examining government official communication patterns and strategies for activation of local resources by geographic location may be useful.

There were notable strengths to this study. The large sample size and study design allowed for accurate representation of the Hispanic population. However, as with all studies there are limitations, including that this is a cross-sectional study and therefore causation cannot be assumed. Additionally, because of the ethnic and income demographic characteristics of the sample, generalization to other non-Hispanic or populations with greater income may not be appropriate. Weighting of the data presented in this study was done to ensure that the sample represented the whole population of the counties of focus. Another limitation found in all interview survey studies is that of interviewees exaggerating or under representing their true views. In this study we conducted careful monitoring of data collection procedures including accompanying interviewers, providing specific probes to questions, and retraining interviewers as needed. A final caveat to consider is that theoretically the constructs of intention to behave and actual behavior are different but shown to be related. A recent meta analysis of 47 experimental studies examining intention and behavior confirm that medium to large changes in intentions engender medium to small behavior change. ${ }^{52}$ Thus, for evacuation planning purposes this study provides a cross sectional view of intention to behave and therefore provides only estimates of actual evacuation behavior. 
In summary, this study investigated intention to comply with mandatory hurricane evacuation orders among a respondent group generally uncharacterized in the literature. Our study results indicate this vulnerable population has high levels of intention to comply with mandatory evacuation orders and showed statistically significant differences in these intentions by age, gender and ethnicity, education, acculturation, county of residence and distance from shoreline. Moreover, given that evacuation failures have occurred amongst equally impoverished populations during past disasters, our results suggest that despite high levels of intentions to comply with evacuation orders, emergency managers must consider how targeted messages, education, and programs can ensure that these good intentions to comply with mandatory orders for evacuation manifest themselves into actual evacuation behavior in the face of a storm.

\title{
Acknowledgments
}

\begin{abstract}
We would like to acknowledge the collaboration of Region 11 Texas Department of State Health Services, Hidalgo County Health and Human Services (HCHHS) and the Cameron County Health Department (CCHD). We especially want to thank, Dr. Brian Smith, Ms. Dina Sosa, and Mr. Thad Kennedy of DSHS, Mr. Eddie Olivarez of HCHHS and Ms. Yvette Salinas of CCHD.
\end{abstract}

We also thank Pablo Sanchez for his support of data management, as well as Vanessa Saldana, Lisa MitchellBennett, Lorraine Bautista and Kendra Stine on the implementation of the project and development of the paper. Thanks to Dr. Susan Fisher-Hoch for her comments on the paper and to the anonymous reviewers.

We would like to express our thanks to the community health workers from Hidalgo and Cameron counties who assisted with the collection of data through door to door surveys.

\section{Funding}

This work was financially supported by the Texas Department of State Health Services (DSHS), \#2008-027641, the CCTS-CTSA award 1U54RR023417-01 funded by the National Center for Research Resources.

\section{Reference List}

1. Bea K. Federal Emergency Management Policy Changes after Hurricane Katrina: a Summary of Statutory Provisions.: DTIC Document. 2006

2. Townsend, FF. The Federal Response to Hurricane Katrina: Lessons Learned. Vol. 1. Washington, DC: Office of the Assistant to the President for Homeland Security and Counterterrorism; 2007. [Retrieved February 2006]

3. Walker, DM. Hurricane Katrina GAO's preliminary observations regarding preparedness, response, and recovery: testimony before the Senate Homeland Security and Governmental Affairs Committee. Diane Publishing; 2006.

4. Bea, K.; Halchin, E.; Hogue, H., et al. Federal Emergency Management Policy Changes After Hurricane Katrina: A Summary of Statutory Provisions. Washington, DC: Congressional Research Service; 2007.

5. Petrolia DR, Bhattacharjee S, Hanson TR. Heterogeneous Evacuation Responses to Storm Forecast Attributes. Natural Hazards Review. 2011; 12:117-125.

6. Redlener I, Johnson D, Berman DA, Grant R. Snapshot 2005: where the American public stands on terrorism and preparedness four years after September 11. The 2005 Annual Survey of the American Public by the National Center for Disaster Preparedness, Columbia University Mailman School of Public Health Accessed. 2007 Mar.30

7. Hewins-Maroney B, Schumaker A, Williams E. Health seeking behaviors of African Americans: implications for health administration. Journal of Health and Human Services Administration. 2005; 28(1):68-95. [PubMed: 16521616] 
8. Elder K, Xirasagar S, Miller N, Bowen S, Glover S, Piper C. African Americans' decisions not to evacuate New Orlenas before Hurricane Katrina: A qualitative study. American Jouranl of Public Health. 2007; 97:S109-S115.

9. Gray-Graves A, Turner KW, Swan JH. The Level of Willingness to Evacuate Among Older Adults. Gerontology \& Geriatrics Education. 2011; 32(2):107-121. [PubMed: 21598145]

10. Gray-Graves AM, Turner KW, Swan JH. Sustainability of seniors: Disaster risk reduction management. The Journal of Aging in Emerging Economies. 2010; 2(2):64-78.

11. Sapir DG. Disaster Data: A Balanced Perspective: Natural disasters in 2007. Center for Research on the Epidemiology of Disasters CRUNCH, Brussels, Belgium. 2008; (8)

12. Smith DC. Organizing for disaster preparedness. Journal of Community Practice. 2006; 13(4):131141.

13. Nates J, Moyer V. Lessons from Hurricane Katrina, tsunamis and other disasters. The Lancet. 2011 Feb.336:1144-1146.

14. Nates JL, Moyer VA. Lessons from Hurricane Katrina, tsunamis, and other disasters. The Lancet. 2005; 366(9492):1144-1146.

15. Bourque LB, Siegel JM, Kano M, Wood MM. Weathering the storm: The impact of hurricanes on physical and mental health. The ANNALS of the American Academy of Political and Social Science. 2006; 604(1):129-151.

16. Centers for Disease Control and Prevention AG. Surveillance for Illness and Injury After Hurricane Katrina--- Three Counties, Mississippi, September 5--October 11, 2005. Morbidity and Mortality Weekly Report. 2006; 55(9):231-234. [PubMed: 16528228]

17. Gabe T, Falk G, McCarty M, Mason VW. Hurricane Katrina: Social-Demographic Characteristics of Impacted Areas. 2005

18. Lowewenberg S. Louisiana looks back on a week of disaster. The Lancet. 2005; 366(9489):881882.

19. Elder K, Xirasagar S, Miller N, Bowen S, Glover S, Piper C. African Americans' decisions not to evacuate New Orlenas before Hurricane Katrina: A qualitative study. American Journal of Public Health. 2007; 97:S109-S115. [PubMed: 17413069]

20. Skinner, R. Committee on homeland security and governmental affairs conference. Hope, AR: 2006. Hurricane preparedness and evacuation.

21. Ajzen I. The theory of planned behavior. Organizational behavior and human decision processes. 1991; 50(2):179-211.

22. Ajzen, I.; Albarracin, D. Predicting and changing behavior: A reasoned action approach. In: Ajzen, I.; Albarracin, D.; Hornik, R., editors. Prediction and Change of Health Behavior: Applying the Reasoned Action Approach. Hillsdale, N.J.: Lawrence Erlbaum Associates Publishers; 2007.

23. Albarracin D, Johnson BT, Fishbein M, Muellerleile PA. Theories of reasoned action and planned behavior as models of condom use: a meta-analysis. Psychological Bulletin. 2001; 127(1):142161. [PubMed: 11271752]

24. Fishbein, ME. Readings in attitude theory and measurement. New York: Wiley; 1967.

25. Hardeman W, Johnston M, Johnston D, Bonetti D, Wareham N, Kinmonth AL. Application of the theory of planned behaviour in behaviour change interventions: A systematic review. Psychology and health. 2002; 17(2):123-158.

26. Blendon R, Benson J, Desroches C, Lyon-Daniel K, Mitchell E, Pollard W. The public's preparedness for hurricanes in four affected regions. Public Health Reports. 2007; 122(2):167176. [PubMed: 17357359]

27. Gladwin, H.; Peacock, WG. Warning and Evacuation: A Night of Hard Choices. In: Peacock, WG.; Gladwin, H., editors. Hurricane Andrew: Ethnicity, Gender and the Sociology of Disasters. New York: Routledge; 1997.

28. Bateman JM, Edwards B. Gender and evacuation: A closer look at why women are more likely to evacuate for hurricanes. Natural Hazards Review. 2002; 3:107-117.

29. Smith S, M C. Fleeing the storm(s): An examination of evacuation behavior during Florida's 2004 hurricane season. Demography. 2009; 46(1):127-145. [PubMed: 19348112] 
30. US Census Bureau. [Accessed December 1, 2010] American community survey 2005-2007. Census Bureau. 2007. Available at: URL: www.factfinder.census.gov

31. Rosenkoetter MM, Covan EK, Bunting S, Cobb BK, Fugate-Whitlock E. Disaster evacuation: an exploratory study of older men and women in Georgia and North Carolina. Journal of Gerontological Nursing. 2007; 12(33):46-54. [PubMed: 18183747]

32. Rosenkoetter MM, Covan EK, Cobb BK, Bunting S, Weinrich M. Perceptions of older adults regarding evacuation in the event of a natural disaster. Public Health Nursing. 2007; 24(2):160168. [PubMed: 17319888]

33. Baker EJ. Predicting response to hurricane warnings: A reanalysis of data from four studies. Mass Emergencies. 1979; 4(1):9-24.

34. Dash N, Gladwin H. Evacuation decision making and behavioral responses: Individual and household. Natural Hazards Review. 2007; 8:69-77.

35. Drabek TE. Human system responses to disaster: An inventory of sociological findings. Springer Series on Environmental Management. 1986

36. Zhang Y, Prater CS, Lindell MK. Risk area accuracy and evacuation from Hurricane Bret. Natural Hazards Review. 2004; 5:115-120.

37. Eisenman D, Cordasco K, Asch S, Golden J, Glik D. Disaster planning and risk communication with vulnerable communities: Lessons from Hurricane Katrina. American Journal of Public Health. 2007; 97:S109-S115. [PubMed: 17413069]

38. Jacob B, Mawson A, Payon M, Guignard J. Disaster mythology and fact: Hurrican Katrina and social attachment. Public Health Reports. 2008; 123(5):555-566. [PubMed: 18828410]

39. Smith S, McCarty C. Fleeing the storm(s): An examination of evacuation behavior during Florida's 2004 hurricane season. Demography. 2009; 46(1):127-145. [PubMed: 19348112]

40. Wilmot CG, Mei B. Comparison of alternative trip generation models for hurricane evacuation. Natural Hazards Review. 2004; 5:170-178.

41. Riad JK, Norris FH, Ruback RB. Predicting Evacuation in Two Major Disasters: Risk Perception, Social Influence, and Access to Resources1. Journal of Applied Social Psychology. 1999; 29(5): 918-934.

42. Whitehead JC, Edwards B, Van Willigen M, Maiolo JR, Wilson K, Smith KT. Heading for higher ground: factors affecting real and hypothetical hurricane evacuation behavior. Global Environmental Change Part B. Environmental Hazards. 2000; 2(4):133-142.

43. Lindell MK, Lu JC, Prater CS. Household decision making and evacuation in response to Hurricane Lili. Natural Hazards Review. 2005; 6:171-180.

44. Baker EJ. Hurricane evacuation behavior. International Journal of Mass Emergencies and Disasters. 1991; 9(2):287-310.

45. Reininger B, McCormick J, Rahbar MH, et al. Medical Special Needs Assessment of Lower Rio Grande Valley. 2008

46. Marin G, Gamba R. A new measurement acculturation in Hispanics: The bidirectional acculturation scale for Hispanics (BAS). Hispanic Journal of Behavioral Sciences. 1996; 8(3):297316.

47. STATA 11.1 Survey Analytic Package [computer program]. College Station, TX: STATA Corp; 2010.

48. Lower Rio Grande Valley Development Council. Needs Assessment Lower Rio Grande Valley Hurricane Dolly Recovery Program. Lower Rio Grande Valley development council. 2011 Available at: URL: www.lrgvdc.org/.../LRGVDC_Needs_Assessment_Combined_PDF_.

49. Dow K, Cutter SL. Emerging hurricane evacuation issues: hurricane Floyd and South Carolina. Natural Hazards Review. 2002; 3:12-19.

50. Blendon, RJ.; Buhr, T.; Benson, JM.; Weldon, KJ.; Herrmann, MJ. Survey of Hurricane Preparedness Finds Those Who Experienced Katrina Most Worried About Drinking Water and Medical Care. Boston, MA: Harvard School of Public Health; 2008.

51. Baezconde-Garbanati L, Unger J, Portugal C, Delgado JL, Falcon A, Gaitan M. Maximizing participation of Hispanic community-based/non-governmental organizations (NGOs) in emergency preparedness. International Quarterly of Community Health Education. 2006; 24(4):289-317. [PubMed: 17686688] 
52. Webb T, Sheeran P. Does changing behavioral intentions engender behavior change? A metaanalysis of the experimental evidence. Psychological Bulletin. 2006; 132(2):249-268. [PubMed: 16536643]

53. The Colonia Initiatives Program Office of the Texas Secretary of State. Tracking the progress of state funded projects that benefit colonias. Senate Bill 99 82nd Texas Legislature Regular Session. 2010 Available at: URL: http://www.sos.state.tx.us/border/forms/reports-11/sb-99-progress.pdf. 

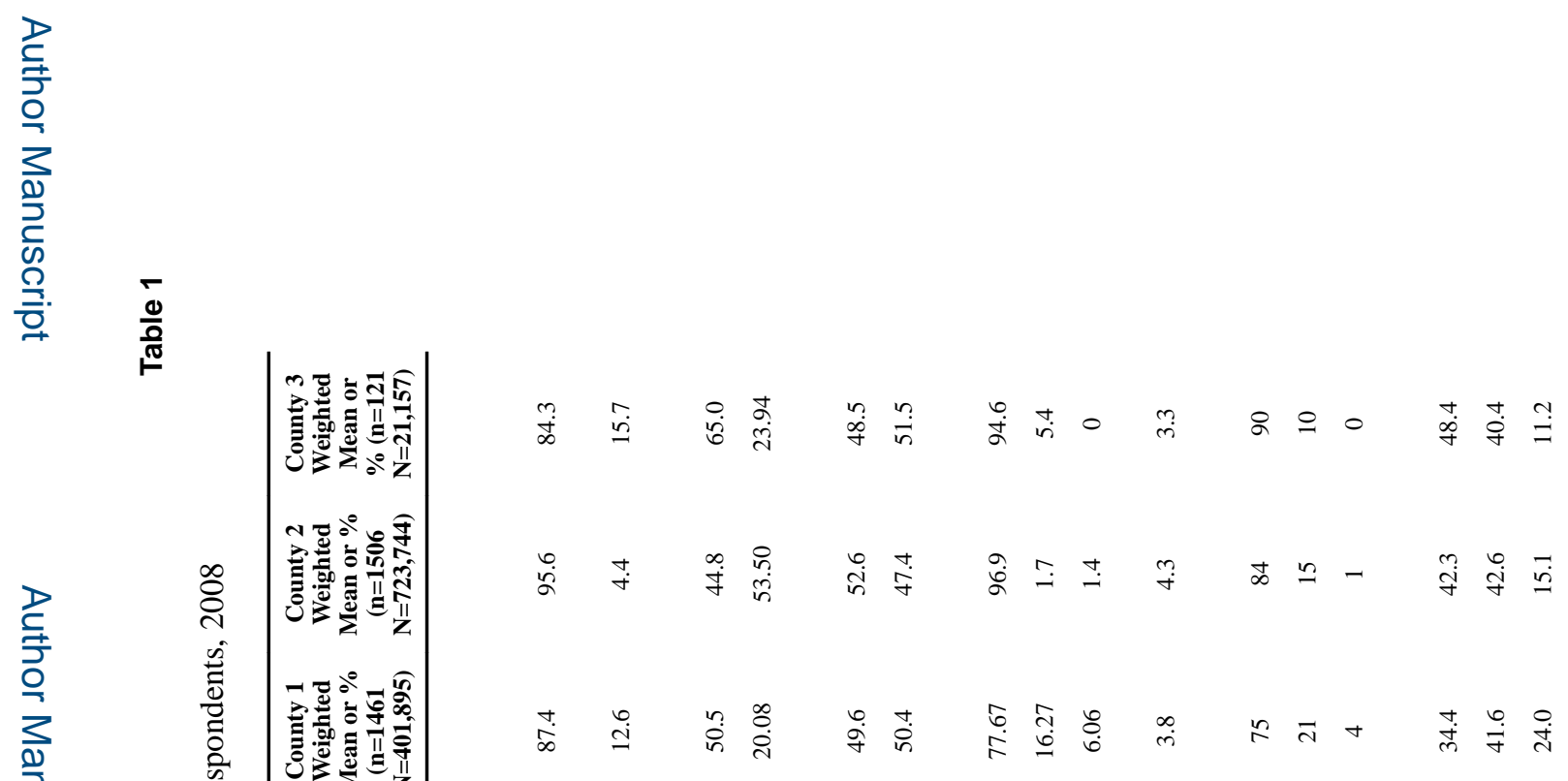

$\frac{\text { 市 }}{\text { 은 }}$

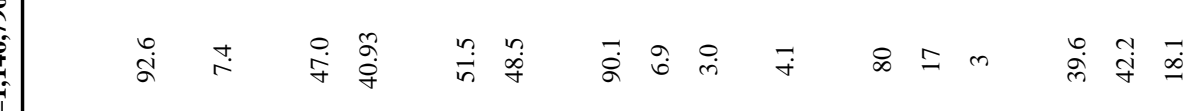

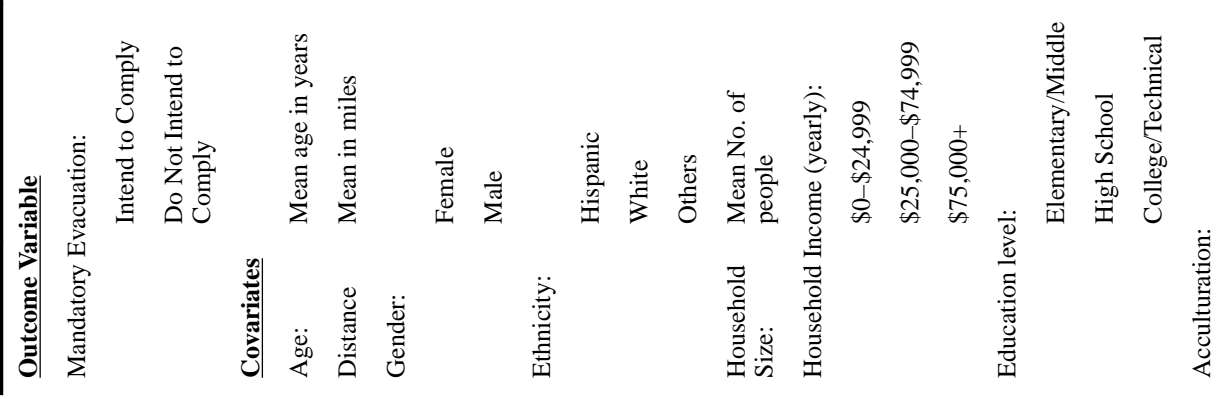
Disaster Med Public Health Prep. Author manuscript; available in PMC 2016 June 16. 
Reininger et al.

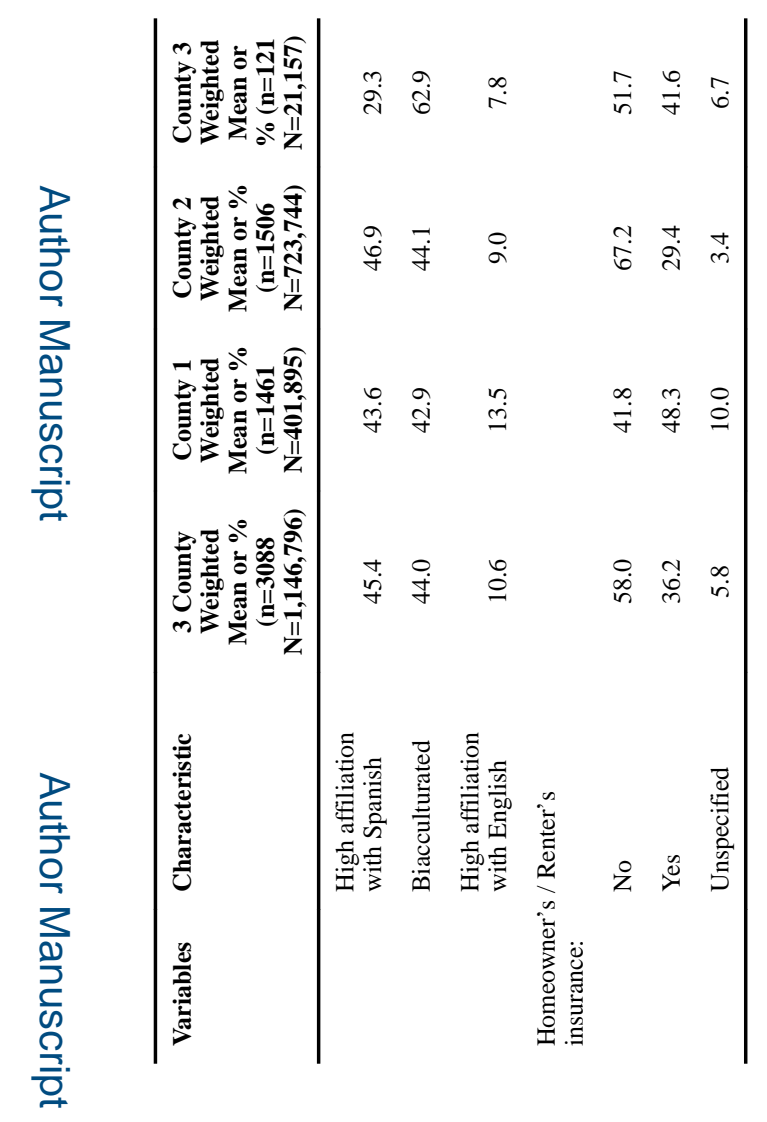

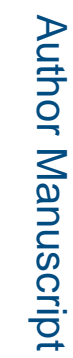

로을

Disaster Med Public Health Prep. Author manuscript; available in PMC 2016 June 16. 
Table 2

Socio-demographic Characteristics among Coastal Respondents who Do Not Intend to Comply and Intend to Comply with Mandatory Evacuation Orders, 2008

\begin{tabular}{|c|c|c|c|c|}
\hline Characteristics & & $\begin{array}{c}\text { Do Not } \\
\text { Comply } \\
(\mathbf{n}=231 \\
\mathbf{N}=\mathbf{8 2 , 5 1 9 )}\end{array}$ & $\begin{array}{c}\text { Comply } \\
(\mathbf{n}=2746 \\
N=\mathbf{1 , 0 2 8 , 1 7 2})\end{array}$ & p-value \\
\hline \multirow{3}{*}{$\begin{array}{l}\text { Gender } \\
(n=2977)\end{array}$} & & & & \multirow{3}{*}{$.000^{*}$} \\
\hline & Male & 86 & 675 & \\
\hline & Female & 145 & 2071 & \\
\hline $\begin{array}{l}\text { Age } \\
(\mathrm{n}=2977)\end{array}$ & & $53.35(1.14)$ & $46.36(0.36)$ & $<0.0001$ \\
\hline \multirow{4}{*}{$\begin{array}{l}\text { Ethnicity } \\
(n=2977)\end{array}$} & & & & \multirow{4}{*}{$.043^{*}$} \\
\hline & Hispanic & 196 & 2450 & \\
\hline & White & 21 & 209 & \\
\hline & Other & 14 & 87 & \\
\hline \multirow{4}{*}{$\begin{array}{l}\text { Income } \\
(n=2977)\end{array}$} & & & & \multirow{4}{*}{.193} \\
\hline & $\$ 0-\$ 24,999$ & 123 & 1832 & \\
\hline & $\$ 25,000-\$ 74,999$ & 38 & 379 & \\
\hline & $\$ 75,000+$ & 8 & 54 & \\
\hline \multirow{4}{*}{$\begin{array}{l}\text { Education level } \\
(\mathrm{n}=2929)\end{array}$} & & & & \multirow{4}{*}{$.004^{*}$} \\
\hline & Elementary/Middle & 90 & 1085 & \\
\hline & High School & 77 & 1154 & \\
\hline & College/Technical & 57 & 466 & \\
\hline \multirow{4}{*}{$\begin{array}{l}\text { Acculturation } \\
(n=2977)\end{array}$} & & & & \multirow{4}{*}{$.000^{*}$} \\
\hline & $\begin{array}{l}\text { High affiliation } \\
\text { Spanish }\end{array}$ & 83 & 1392 & \\
\hline & $\begin{array}{l}\text { Moderately } \\
\text { acculturated }\end{array}$ & 126 & 1082 & \\
\hline & $\begin{array}{l}\text { High affiliation } \\
\text { English }\end{array}$ & 22 & 272 & \\
\hline \multirow{4}{*}{$\begin{array}{l}\text { County } \\
(n=2977)\end{array}$} & & & & \multirow{4}{*}{$.000^{*}$} \\
\hline & County 1 & 160 & 1229 & \\
\hline & County 2 & 57 & 1416 & \\
\hline & County 3 & 14 & 101 & \\
\hline
\end{tabular}


Table 3

Adjusted Odds Ratios (AOR) for Coastal Respondents' Intention to Comply with Mandatory Evacuation Order, 2008

\begin{tabular}{|c|c|c|c|c|}
\hline Variables & Description & AOR & $\begin{array}{l}\text { 95\% Confidence } \\
\text { Interval }\end{array}$ & $\begin{array}{c}\mathbf{P} \\
\text { Value }\end{array}$ \\
\hline Age: & Years & 0.98 & $(0.97 ; 0.99)$ & 0.000 \\
\hline \multicolumn{5}{|c|}{ Gender and Ethnicity: } \\
\hline & Male Hispanic & 1.0 & Referent & - \\
\hline & Male White & 2.8 & $(1.3: 6.2)$ & 0.012 \\
\hline & Female Hispanic & 1.6 & $(1.3: 2.0)$ & 0.000 \\
\hline & Female White & 1.9 & $(1.1: 3.0)$ & 0.015 \\
\hline \multicolumn{5}{|c|}{ Education level: } \\
\hline & Elementary/Middle & 1.0 & Referent & - \\
\hline & High School & 1.4 & $(1.02 ; 1.9)$ & 0.037 \\
\hline & College/Technical & 0.7 & $(0.5 ; 0.97)$ & 0.033 \\
\hline \multicolumn{5}{|c|}{ Acculturation: } \\
\hline & $\begin{array}{l}\text { High affiliation } \\
\text { Spanish }\end{array}$ & 1.0 & Referent & - \\
\hline & Bi- acculturation & 0.5 & $(0.4 ; 0.6)$ & 0.000 \\
\hline & $\begin{array}{l}\text { High affiliation } \\
\text { English }\end{array}$ & 0.6 & $(0.4 ; 0.97)$ & 0.037 \\
\hline \multicolumn{5}{|l|}{ County: } \\
\hline & County 1 & 1.0 & Referent & - \\
\hline & County 2 & 9.3 & $(5.2 ; 16.7)$ & 0.000 \\
\hline & County 3 & 1.1 & $(0.9 ; 1.3)$ & 0.502 \\
\hline Distance: & Miles & 0.97 & $(0.95 ; 0.98)$ & 0.000 \\
\hline
\end{tabular}

